\title{
Cross-cultural translation principles and applied research under the multicultural background
}

\author{
Xia LI \\ Chengdu Polytechnic \\ Chengdu,Sichuan,610041 China
}

\begin{abstract}
The human culture is colorful, its dissemination activities and contents also appear colorful, especially when the human society went into the information age, the field of human communication activities were further expanded, the content of distribution have a different nature features, communication theory in social, cultural, economic, technological and other activities are widely used, showing the spread of modern research in all areas of social life and to promote the application. In the framework of multi-cultural, cross-cultural translation from the perspective of intercultural communication principles to build channels of communication between diverse cultures, it provides solution for translation about new and old problems under the background of globalization. With the rapid development of cultural exchange, we should grasp the scientific principles of cross-cultural translation, adaptation and realistic, long-lasting expand its exploration and research.
\end{abstract}

Keywords-Cross-cultural
multiculturalism, applied research $\quad$ principles,

\section{INTRODUCTION}

Translation is very complex, language differences, cultural differences, ideological differences, the translator's language skills, cultural awareness and understanding of the structure constituted by its worldview, values, ideology, etc. and all of them will have a significant impact on the translation. Among them, the impact of cultural differences on translation activities in translation study attracts more and more attention in the past two decades, although the meaning of a language translation express through another language, but the language reflects culture, carrying the rich cultural connotations, and is subject to cultural constraints, and the use of language, words can best embody the cultural information that language bearing, reflecting human social life. Vocabulary as the basic unit of language, especially loaded with a specific cultural connotation words, played a decisive role in translation. How can I properly pass these words in the cultural connotation is always being a translation problem.

\section{THE MEANING OF CROSS-CULTURAL}

The so-called "cross-cultural" refers to in globalization a social phenomenon that social mobility increasing and racial mixing caused by the nature of this phenomenon is changing the traditional and the existing culture and the creation of a new culture. Cross-culture in different countries across cultural and national boundaries, cultural differences among people, countries and groups across the system through an interactive relationship the attributions of cultural experiences between people. From an academic speaking, the so-called "cross-cultural" refers to participants in the exchanges not only rely on your own code, habits, attitudes and behavior, but also experience and understand of each other's code of all relationships, habits, attitudes and patterns of behavior; from cultural theory perspective, cultural identity, refers to human groups or individuals belonging and acceptance for a particular culture, which has cultural value. The so-called "cross-cultural", means across different countries and different ethnic and cultural boundaries, cross cultural interaction refers to two groups with different cultural backgrounds and above it. Production of goods and labor does not mean the product of labor in the labor embodied in a variety of useful properties, but to the common human labor. In short, the "cross-cultural" refers to the interaction between the system by crossing cultural boundaries to experience the vesting of all human relationships.

\section{THE PROPOSITION OF CROSS-CULTURAL TRANSLATION}

With grow of interaction in inter-cultural exchanges. Many scholars have noted, "From a cultural perspective to examine translations make us suddenly enlightened," we began to try from the perspective of intercultural communication to revisit translation problem, the principle of cross-cultural translation.

Cross-cultural translation principles break through the restriction of corresponding language code-switching. From the height of exchange and communication systems concept of global culture between different cultures and languages to build between multicultural channel, to promote deeper understanding and communication between cultures, but also to solve the problem of translation of new ideas. As cross cultural communication activities, translation should uphold the principle of cross-cultural communication, focused on a different basis in the original system, code-conversion between discourses or language equivalent, considered the influence of culture, language, rich culture, to achieve transmission and communication and deep-seated ideological connotations on. This is mainly reflected from the following three parties: 


\section{A. Focus on cultural connotations oflanguage, push the boundaries of language}

Rich content makes human society vastly different cultures. Language is the product and expression of human society. Cultural diversity determines the meaning of the richness of language, language learning process should focus on the cultural connotations of language. Each language and culture has its own advantages and characteristics, are also confined to their limited field of view. Philosopher Wittgenstein declared: "The limits of my language mean the limits of my world." Heidegger once said: "Language is there home." Translation should break through the perspective of single language boundaries or limitations caused by build multicultural bridges, trying to translate the various cultural integration in a language which.

\section{B. Respect for cultural diversity}

Each culture is adapted to different environments by accumulated experiences; it provides different solutions for the same goal, the same thing. International situation, under different environments, each culture are likely to play their strengths in different areas and times. Cultural diversity is a basic form of human cultural existence; it is the source of the core and the creation of communication. Culture is an important national genetic, cultural diversity can help us to maintain peace and development in the world; you can also make human society to achieve sustainable development. In 2007, 33rd UNESCO held in Paris adopted the Convention on the protection of cultural diversity. Cross-cultural translation principles should also respect and consciously safeguard cultural diversity.

\section{Developing Intercultural Communication Literacy}

Under the premise of respect for cultural diversity, indepth understanding of both cultures, it breaking the boundaries of language and culture, finding the transition point between the two cultures, emphasizing mutual respect and the principle of equality of exchanges, enhancing mutual understanding, preventing ethnic inferiority or ethnocentric psychology. Through cultural exchange between parties involved in the original rich cultural system, broaden the original cultural horizons.

\section{CROSS-CULTURAL TRANSLATION PRINCIPLES}

The basic principle of cross-cultural translation is "faithful first, to create a second" and "content first, in the form of a second."

\section{A. Faithfulfirst, to create a second}

Translation in a certain sense is really a re-creation of the translator. However, this "creation" is relative, conditional, and is loyal to convey the semantics of the original language and culture as a precondition; because "the purpose of translation is to make the reader through their own words to learn other countries culture, that the translator introduced primitive culture through the target language to the target language readers, in other words, is to do everything possible to strive to "make people understand the original translation by knowing, understanding or appreciating the idea of original content and stylistic." The "ideological content" including both the original languages of the semantic content, and the original languages of the cultural content; on this basis, going to convey the style of the original language are higher-level objectives and requirements "To achieve this purpose, it must pursue the objective meaning of the language between the original language, semantic similar, similar style, and the style of the match. "This determines that we must put "faithful "as the first principle of translation.

\section{B. Content of the first, second form}

The so-called content, obviously referring to the primitive language itself contains semantic meaning, culture and emotion, the so-called form; it refers to the primitive "content" in order to express the language of the shell, including the original text of the genre, the statement discourse structure and rhetorical device etc. In cross-cultural translation faithfully transmit the objective requirements of primitive cultures, it make us able to maximize the most accurate representation of the semantic content of the original language with the target language culture in particular, the level of content as an important criterion for judging the quality of translation. Cao Minglun in addressing the problem of Shakespeare's sonnets translation when he said: "in the translation the reason to take 'pretty clothes' and discard 'intrinsic value', or say take 'peel' and discard 'flesh', the reason lies Over the years, focusing on multi-language trans lator to convert level, ignoring the his torical and cultural dimensions of the cross, so it must put translation treatment content, accurate of content in the first place, of course, if we can take into account the form of the original language, it will be more conducive to convey primitives stylistic when maintaining the original form can not effectively express the original content, it would sacrifice form in pursuit of accurate content, be sure not to stick to the original form. "Form" attached to "content ", serve for "Content ", therefore pursuing the form must not damage the content. Opposites relationship between the two can be summarized as" content first, in the form of a second "principle, which is the" faithful first, to create second, "the best interpretation.

\section{CROSS-CULTURAL TRANSLATION APPLICATION UNDER MULTICULTURAL BACKGROUNDS}

\section{A. Cards are shown to explain the inherent aesthetic use in translation}

Commentary translation cards are shown to reflect the aesthetic taste of different nationalities. Significant differences in Chinese and English on the national aesthetic habits are the result of historical and cultural traditions, and to restrict the way and appreciate the aesthetic habits of various ethnic groups, it resulting in a very different language to express their own style. History, culture and life experiences precipitation language users within the context of a specific language, so that they have different as sociations in the use of a specific vocabulary.

Chinese scenery description consistently emphasized that "Italy and throughout the financial" realm, the pursuit of the objective and subjective emotional scene is high degree of 
harmony, totally blend of beauty, is "virtual" and "real" unique combination. This is es sentially a virtual image with a lot of ambiguity, how much scenery description adds some "virtual" exaggeration that depicted some real distortion, producing an image of the United States and hazy blur, which is the Chinese scenery pursuit of aesthetic effect. English scene description does not. English use more vivid sense of the concrete by means of the image of the objective to reproduce lifelike scenery, not deliberately do too much rhetoric on depicting imagery rendering. It mostly clear objective in line with the language of reason is standing outside to enjoy the natural beauty of nature. Thus, in many cases, often with a simple list instead of the scene to convey the mood of deepening the real scene of beauty to reach the West "imitating nature", "reproduction of reality" aesthetic effect. So it's not so much the language of human color, subtle beauty and virtual imagery rendering. Although it is also used hyperbole, personification when other rhetorical devices, but in the expression of real, physical, and strive to accurately and clearly not out of shape, so when the contingent word sentences often seems simple objective.

\section{B. Cross-cultural translation in cultural tourism in the use of information processing}

Tourism in English translation, it spread Chinese culture of responsibility, and understand Chinese culture is one of the main purposes of tourists in China. For this reason, it is necessary to solve the problem of cross-cultural relations in political difference, racis $m$, racial prejudice, and to deal with effectively cross-cultural conflict and intergroup conflict, the use of cross-cultural awareness to deal with some cultural information and seek to understand. Nida once said: "If the translator does not adjust the load information to the imaginary reader, the recipient may lose some of the key factors in the information, or think too hard to stop reading the translation." During the English translation of tourist attractions for foreign tourists to eliminate difficulties in understanding, the translator should be adjusted as appropriate from the perspective of cross-cultural communication, addition or deletion of the corresponding cultural background explanations or comments.

\section{Cross-cultural translation in the translation of historical figures and historical events}

China is an ancient culture has a long history in the country. In the introduction heritage, they often involve many historical figures and historical events, while foreign tourists to these historical figures and historical events are not familiar with. Therefore, in the translation of these historical figures and his torical events, our principle aim is to spread Chinese culture, can be literal, translation, transliteration and other methods, but under what circumstances the use of which translation needs have a keen translator cross-cultural awareness. Like the translation of "The First Emperor". Most of the foreign tourists who do not know Qin Shihuang, in the translation of these historical figures, it is best to increase the relevant background information about the identity of this historical figure as well as his achievements in the history of the position and so on.

\section{Cross-cultural translation of the commentary choose to use}

Nowadays, writing Chinese tourist information in the description of an attraction, often prefer allusive, piling idioms, shop. How to choose an accurate translation of English words to let the world grow up in different cultures, with different values and behavioral norms of human and cultural backgrounds different from their own people communicate? Many translators and guides often choose to tell the story introduce tourist attractions. But if the foreign tourists do not understand the cultural background of our country, no matter how you put vivid, clear, and often they will be misunderstood. Therefore, we choose the vocabulary translation must be noted that the use of cross-cultural awareness and foreign tourists in the race, political stereotypes and prejudices and other cultural backgrounds into account, in order to tolerance and understanding.

\section{CONCLUSIONS}

In short, cross-cultural communication and promote translated into the national cultural bridge, is a simple and quick and most effective communication platform. Concept of cultural translation in cultural center, cultural factors are more reserved, protecting vulnerable culture and promote cultural diversification, so since the 1990s, gradually recognized and accepted translation industry. After entering the new century, an important means of global cultural exchanges become more frequent, translation has become a cross-cultural communication. Therefore, the Chinese translation we should pay more to BASSNETT cultural translation theory as a guide, follow the principle of alienation-based translation, as much as possible to allow foreign friends understand Chinese culture, love of Chinese culture.

\section{REFERENCES}

[1] Wang Yingpeng. Translation function Horizon intercultural communication research [D]. Shanghai International Studies University, 2012.

[2] Wang Shouhong. Intercultural language translation strategies propaganda Studies Perspective [D] with the Shanghai International Studies University, 2012.

[3] Zhu Yihua. Propaganda translate research system constructed to explore [D]. Shanghai International Studies University, 2013.

[4] Wu Sha. Cross-Cultural Perspective spread under the "Art of War" Translating research [D]., Central South University, 2012.

[5] Xiong Xin. China Dishes intercultural communication theory under the English translation of research [D]. Shanghai International Studies University, 2013.

[6] Kongzi. Under the principle of cross-cultural translation multicultural framework. [J]. Mass business, 2009,20:202-203.

[7] Yan Pei Wen. Opposites concept of harmony in the Perspective of cross-cult ural translat ion principles and strategies [J]. Yuejiangzhong SCIENCE, 2010,04:115-120.

[8] Yang Yuangang. Comparative cultural study of English and Chinese words semantics [D]., East China Normal University, 2005. 